Delnoij, D., Hendriks, M. De CQ-index: het meten van klantervaringen in de zorg. TSG: Tijdschrift voor Gezondheidswetenschappen: 2008, 86(8), 440-446

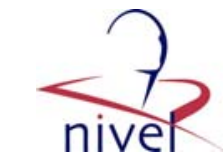

\begin{tabular}{|l|l|}
\hline Postprint Version & 1.0 \\
\hline Journal website & http://vb23.bsl.nl/frontend/redir.asp?page=1388-7491/tsg86-440.pdf \\
\hline Pubmed link & \\
\hline DOI & \\
\hline
\end{tabular}

This is a NIVEL certified Post Print, more info at http://www.nivel.eu

\title{
De CQ-index: het meten van klantervaringen in de zorg
}

\author{
DiANA DELNOI**, MiCHELle HENDRIKS**
}

* Centrum Klantervaring Zorg, Utrecht / TRANZO, Universiteit van Tilburg

** NIVEL, Nederlands instituut voor onderzoek van de gezondheidszorg, Utrecht

Mw. D. Delnoij, Centrum Klantervaring Zorg, Postbus 1568, 3500 BN Utrecht, tel. 030-

2729800, e-mail: d.delnoij@centrumklantervaringzorg.nl

In dit artikel wordt de Consumer Quality Index (CQ-index of CQI) beschreven. De CQ-index is een gestandaardiseerde systematiek voor het meten van ervaringen van patiënten/cliënten met de zorg. Een essentieel kenmerk is dat patiënten/cliënten, zorgaanbieders en zorgverzekeraars betrokken worden bij het ontwikkelen van een CQI meetinstrument. Op dit moment zijn er zeven CQI meetinstrumenten beschikbaar voor verschillende vormen van zorg en wordt er gewerkt aan de ontwikkeling van ongeveer twintig CQI meetinstrumenten. Het doel van de CQ-index is het bevorderen van transparantie over prestaties van zorgaanbieders en zorgverzekeraars gezien vanuit patiëntenperspectief. De informatie moet bruikbaar zijn voor de kiezende zorgconsument en voor de zorginkoop van zorgverzekeraars. Daarnaast is het idee dat zorgverleners de informatie gebruiken voor het opzetten van verbetertrajecten. Om te zorgen voor de ontwikkeling, wetenschappelijke waarborging, implementatie en bewaking van de CQ-index is het Centrum Klantervaring Zorg opgericht. De financiering van de ontwikkeling van CQI meetinstrumenten en wetenschappelijk onderzoek rondom de CQ-index komt uit een combinatie van publieke en private middelen. Voor de komende jaren is het belangrijk om te zorgen dat voor de zorggebieden met het meeste maatschappelijke belang CQI meetinstrumenten ontwikkeld worden en om te onderzoeken of de beoogde effecten op de marktwerking binnen de zorg optreden.

\section{INLEIDING}

De Nederlandse overheid heeft de afgelopen jaren veel veranderingen doorgevoerd binnen de gezondheidszorg om zo het Nederlandse zorgstelsel om te vormen van een aanbodgestuurd tot een vraaggestuurd zorgstelsel. De bedoeling is dat patiënten een meer centrale rol krijgen: zij moeten meer dan ooit zelf keuzes maken in de zorg. De gedachte hierachter is dat goed geïnformeerde, kritische consumenten zullen kiezen voor kwalitatief goede zorg tegen een scherpe prijs. Ook zorgverzekeraars hebben een grotere verantwoordelijkheid om bij hun zorginkoop de wensen van de patiënten en de mogelijkheden van de aanbieders op elkaar af te stemmen. De zorgaanbieders worden op deze manier gestimuleerd tot betere prestaties. De overheid houdt toezicht op de prestaties 
van het gezondheidszorgsysteem (onder andere door middel van prestatie-indicatoren) en blijft verantwoordelijk voor de toegankelijkheid tot kwalitatief goede zorg en voor de betaalbaarheid. Dit alles moet resulteren in meer concurrentie en marktwerking, en uiteindelijk tot een vermindering van kosten en een hogere efficiëntie en klantgerichtheid binnen de gezondheidszorg. ${ }^{1}$

Eén van de voorwaarden voor het slagen van de marktwerking in de zorg is transparantie over de prijs, toegankelijkheid en kwaliteit van de zorg die wordt verleend. Die transparantie draagt ook bij aan de publieke verantwoording van zorginstellingen en beroepsbeoefenaren. In lijn met een vraaggestuurde benadering is het belangrijk om de kwaliteit van de zorg en dan vooral de klantgerichtheid te meten vanuit het perspectief van de patiënt of zorgconsument zélf. Dit themanummer van TSG gaat over de Consumer Quality Index, afgekort als CQ-index of CQI. De CQ-index is de Nederlandse standaard voor het meten van klantervaringen in de zorg.

De introductie van de CQ-index als meetstandaard is een reactie op de onvergelijkbaarheid van bestaande vragenlijsten en methoden voor het meten van klanttevredenheid / klantervaringen in de Nederlandse gezondheidszorg. Tot nu toe werd de kwaliteit van de zorg vanuit patiëntenperspectief door verschillende instanties en onderzoeksbureaus en op veel verschillende manieren onderzocht. Zolang het doel van deze metingen was het verbeteren van de klantgerichtheid binnen één instelling of beroepsgroep, vormde het naast elkaar bestaan van verschillende vragenlijsten en meetmethoden geen probleem. Maar met de introductie van het nieuwe zorgstelsel ontstaat behoefte aan vergelijkende informatie over prestaties van zorgaanbieders en zorgverzekeraars, niet alleen als het gaat om effectiviteit en veiligheid van de zorg, maar ook als het gaat om klantgerichtheid.

Standaardisering van het meten van klantervaringen in de zorg is nodig om te komen tot vergelijkende keuze-informatie voor consumenten en zorginkopers en om inzicht te krijgen in de klantgericht van de zorg in Nederland. In 2006 is daarom de CQ-index geïntroduceerd als een gestandaardiseerde systematiek voor het meten, analyseren en rapporteren van klantervaringen in de zorg. Nederland is daarmee samen met Engeland en de Verenigde Staten één van de weinige landen waar deze klantervaringen systematisch en gestandaardiseerd gemeten worden. In dit artikel wordt geschetst wat de CQ-index is, wat het doel van de CQ-index is, welke CQI meetinstrumenten ontwikkeld zijn/worden en welke informatie de CQ-index oplevert. Ook wordt ingegaan op de rol van het Centrum Klantervaring Zorg bij het ontwikkelen en beheren van de CQ-index en wordt beschreven hoe de ontwikkeling van de CQ-index wordt gefinancierd. Het artikel sluit af met een beschouwing van enkele aandachtspunten voor de komende jaren.

\section{WAT IS DE CQ-INDEX?}

De CQ-index is een wetenschappelijk gefundeerde, gestandaardiseerde systematiek die zorgbreed kan worden ingezet om de ervaringen van patiënten/cliënten met de aan hen verleende zorg te meten. Dat is een belangrijk verschil ten opzichte van veel andere vragenlijsten, waarin naar tevredenheid van patiënten/consumenten wordt gevraagd. Vragen naar concrete ervaringen van zorggebruikers leveren beter bruikbare informatie op voor kwaliteitsborging en kwaliteitsverbetering dan meer subjectieve vragen naar tevredenheid. ${ }^{2}$

De CQ-index bestaat uit: (1) een serie meetinstrumenten die kwaliteit van zorg meten vanuit het perspectief van de zorggebruiker en dan met name klantgerichtheid en (2) richtlijnen en werkinstructies met betrekking tot steekproeftrekking, dataverzameling, analyse en rapportage. Deze richtlijnen zijn vastgelegd in het Handboek CQI Metingen. ${ }^{3}$ CQI meetinstrumenten meten:

- wat zorggebruikers belangrijke kwaliteitsaspecten van zorg vinden (zogenaamde belangscores);

- hoe vaak de geleverde zorg voldoet aan deze kwaliteitsaspecten;

- in welke mate zorggebruikers problemen ervaren met de toegankelijkheid van zorg; 
- hoe zorggebruikers de geleverde zorg beoordelen.

De CQ-index is qua systematiek gebaseerd op een combinatie van twee meetmethoden: de CAHPS en QUOTE systematiek. De CAHPS-meetinstrumenten, wat staat voor Consumer Assessment of Healthcare Providers and Systems, hebben hun oorsprong in de Verenigde Staten (zie https://www.cahps.ahrq.gov/default.asp) ${ }^{4-6}$ en zijn voor de Nederlandse zorgmarkt aangepast door de afdeling Sociale Geneeskunde van het AMC en het NIVEL op initiatief van zorgverzekeraar Agis. De eerste meetinstrumenten uit de 'familie' die nu CQindex heet, waren de vertaalde CAHPS 3.0 Adult Commercial (een vragenlijst over prestaties van zorgverzekeraars; ${ }^{7}$ ) en de vertaalde Hospital CAHPS. ${ }^{8}$ De QUOTEmeetinstrumenten, wat staat voor QUality Of care Through the patients' Eyes, zijn ontwikkeld door het NIVEL voor de Nederlandse situatie (zie www.nivel.nl/quote). ${ }^{9-11}$ Voor zowel CAHPS en QUOTE-instrumenten geldt dat ze ervaringen van consumenten met de zorg meten, dat het fundament bestaat uit een mix van kwalitatief en kwantitatief onderzoek en dat in het ontwikkelingsproces een belangrijke rol is weggelegd voor de gebruikers van zorgvoorzieningen. Naast overeenkomsten zijn er ook verschillen tussen de twee meetmethoden. In de CAHPS-vragenlijsten wordt relatief veel aandacht geschonken aan de toegankelijkheid van zorg en de mate waarin zorggebruikers gebrekkige toegankelijkheid als een probleem ervaren. QUOTE-vragenlijsten gaan dieper in op aandoeningspecifieke aspecten van kwaliteit van zorg en vragen expliciet naar het belang dat zorggebruikers toekennen aan kwaliteitsaspecten. Al deze kenmerken zijn overgenomen in de CQ-index.

Een essentieel kenmerk van de CQ-index is dat de kwaliteitsaspecten die de zorggebruikers zelf belangrijk vinden een plaats krijgen in het te ontwikkelen meetinstrument. Dit betekent dat de beoogde doelgroep (ofwel de specifieke groep zorggebruikers waarop het CQI meetinstrument is gericht) betrokken moet worden bij het ontwikkeltraject. Per CQI meetinstrument wordt via groepsgesprekken en/of diepte-interviews inzicht verkregen in de wijze waarop het concept 'klantgerichtheid' door de doelgroep wordt geoperationaliseerd in de vorm van concrete aspecten.

Ook is het noodzakelijk dat de CQI meetinstrumenten op (bestuurlijk) draagvlak berusten van de drie partijen in de zorg: patiënten/cliënten, zorgaanbieders en zorgverzekeraars. Om voldoende draagvlak te creëren, spelen deze partijen een belangrijke rol in verschillende fasen van het ontwikkeltraject van een CQI meetinstrument. Deze inbreng is belangrijk op drie momenten:

1. Bij de transformatie van een maatschappelijke vraag of probleem naar een onderzoekbare vraagstelling: Op welke terreinen is een CQ-index nodig? Hoe kan dat terrein en de te bevragen doelgroep worden afgebakend?;

2. Bij de operationalisatie van globale en abstracte kwaliteitsdomeinen in concrete enquêtevragen;

3. Bij de presentatie van de meetresultaten in diverse rapportageformats.

De inbreng van betrokken partijen is in de ontwikkelfase van een CQI meetinstrument geregeld via begeleidende werkgroepen waarin altijd vertegenwoordigers van patiënten/consumenten, van zorgverzekeraars en van zorgaanbieders zitting hebben. De begeleidende werkgroepen fungeren als klankbordgroep voor de onderzoekers die het meetinstrument aan het ontwikkelen zijn.

\section{HET DOEL VAN DE CQ-INDEX}

Het doel van de CQ-index is het bevorderen van de transparantie over prestaties van zorgaanbieders en zorgverzekeraars gezien vanuit patiëntenperspectief. De informatie hierover moet bruikbaar zijn voor verschillende partijen. De belangrijkste eindgebruikers en hun informatiebehoefte staan weergegeven in Box 1.

Kiezende zorgconsumenten hebben keuze-informatie nodig. Zij willen bijvoorbeeld weten welke zorgaanbieder het beste presteert, of zij willen weten hoe hun eigen zorgverlener het 
doet in vergelijking met anderen. Ook zorgverzekeraars en de Inspectie voor de Gezondheidszorg zijn geïnteresseerd in vergelijkende informatie. De Inspectie wil bijvoorbeeld voor het gelaagd en gefaseerd toezicht weten welke aanbieders slechter dan gemiddeld scoren. Voor zorgverzekeraars die in hun inkoopcontracten afspraken willen maken met zorgaanbieders over de klantgerichtheid van zorg (zogenaamde pay-forperformance afspraken) is niet alleen vergelijkende informatie interessant, maar kan het ook relevant zijn om de prestaties van één zorgaanbieder in de tijd te monitoren.

Maar het gaat nog een stap verder. Gegeven dat er dan tóch klantervaringen gemeten gaan worden met het oog op transparantie, is het belangrijk dat zo op te zetten dat ook de zorgmanagers en de beroepsbeoefenaren -dus zij die uiteindelijk verantwoordelijk zijn voor de geleverde kwaliteit- iets met die informatie kunnen doen. Hiervoor hebben zij gedetailleerde informatie nodig die ze kunnen relateren aan de interne bedrijfsprocessen waarop zij sturen. De informatie moet managers en zorgverleners stimuleren om verbeteracties in gang te zetten daar waar de zorg beter kan. De CQ-index moet bovendien aansluiten bij de toetsingskaders met prestatie-indicatoren die in veel zorgsectoren worden ontwikkeld. Op deze manier is de CQ-index bruikbaar voor zorgaanbieders om publieke verantwoording af te leggen over de mate waarin zij klantgericht werken. De toetsingskaders omvatten naast indicatoren voor klantgerichtheid ook zogeheten zorginhoudelijke indicatoren (effectiviteit en veiligheid).

De overheid kan de geaggregeerde informatie uit CQI metingen gebruiken om zicht te krijgen op de klantgericht van de zorg in Nederland en om die klantgerichtheid te monitoren, bijvoorbeeld via de Zorgbalans. Voor onderzoekers leveren CQI metingen tenslotte nuttige informatie op voor het beantwoorden van velerlei wetenschappelijke vragen. Kortom, één keer meten, meerdere keren gebruiken. Waarbij afhankelijk van de behoefte van de gebruikers verschillende 'informatieproducten' worden gemaakt, die qua medium, mate van detail, technische achtergrondinformatie en dergelijke kunnen verschillen.

\section{[BOX 1]}

\section{CQI MEETINSTRUMENTEN IN ONTWIKKELING}

Hoe de ontwikkeling van een CQI meetinstrument in zijn werk gaat, is te lezen in het artikel van Rademakers et al. in dit nummer. Op dit moment zijn er zeven CQI meetinstrumenten ontwikkeld en beschikbaar (zie www.centrumklantervaringzorg.nl) voor verschillende vormen van zorg. Het gaat om de CQI Zorg en Zorgverzekering, CQI Verpleging, Verzorging en Thuiszorg (VV\&T), CQI Gehandicaptenzorg, CQI Staaroperatie, CQI Heup-/Knieoperatie, CQI Diabetes en de CQI Huisartsenzorg Overdag. Daarnaast wordt gewerkt aan de ontwikkeling van ongeveer twintig CQI meetinstrumenten (Zie Box 2 voor een overzicht). Ieder CQI meetinstrument richt zich op een afgebakende doelgroep. Deze doelgroepen variëren van heel algemeen tot specifiek. We onderscheiden de volgende drie subgroepen van CQI meetinstrumenten:

- meetinstrumenten op sectorniveau zoals de CQI Gehandicaptenzorg;

- meetinstrumenten op (specifiek) zorgaanbiederniveau zoals de CQI Fysiotherapie;

- meetinstrumenten op het niveau van specifieke patiëntengroepen of aandoeningen en/of specifieke ingrepen of behandelingen en/of zorgketens, zoals de CQI Diabetes of CQI Staaroperatie.

\section{[BOX 2]}

\section{INFORMATIE UIT DE CQ-INDEX}

Binnen de CQ-index wordt een onderscheid gemaakt tussen drie soorten rapportages op basis van de drie belangrijkste partijen die CQI informatie kunnen gebruiken: een 
consumentenrapportage, een zorginkooprapportage en een verbeterrapportage. Deze drie rapportagevormen zijn alle belangrijk als het gaat om kwaliteitsverbetering in de zorg en in principe dient elke CQI meting te resulteren in zowel een consumentenrapportage als zorginkoop- en verbeterrapportages. Hieronder wordt kort beschreven welke informatie in de rapportages weergegeven wordt.

\section{Consumentenrapportage}

Voor de kiezende consument is het belangrijk dat de prestaties van de verschillende zorgaanbieders of zorgverzekeraars onderling met elkaar vergeleken worden. Voor deze vergelijkende informatie wordt zogenaamde sterreninformatie gecreëerd, welke op naam van de zorgaanbieder of zorgverzekeraar aan de consument wordt gepresenteerd. De zorgaanbieders/zorgverzekeraars worden per gemeten thema in drie groepen ingedeeld: benedengemiddeld $(*)$, gemiddeld $(* *)$ en bovengemiddeld $(* * *)$. De internetsite www.kiesBeter.nl is één van de belangrijkste kanalen waarlangs vergelijkende informatie op basis van ervaringen van zorggebruikers voor consumenten beschikbaar wordt gesteld.

\section{Zorginkooprapportage}

De vergelijkende informatie over de verschillende zorgaanbieders (sterreninformatie) wordt ook in de zorginkooprapportage weergegeven. De zorgverzekeraars kunnen deze informatie gebruiken bij de inkoop van zorg bij individuele zorgaanbieders. Daarnaast geeft de rapportage een algemeen beeld van de klantervaringen in de sector door meer gedetailleerde informatie op itemniveau weer te geven in de vorm van staafdiagrammen. Deze informatie kan door zorgverzekeraars worden gebruikt om prioriteiten te stellen in het inkoopbeleid.

\section{Verbeterrapportage}

De verbeterrapportage wordt voor iedere afzonderlijke zorgaanbieder of zorgverzekeraar opgesteld. Met behulp van de sterreninformatie laat de rapportage de zorgaanbieder zien op welke thema's hij relatief hoog scoort ten opzichte van andere aanbieders en op welke thema's hij relatief laag scoort. Ook in deze rapportage wordt meer gedetailleerde informatie op itemniveau gegeven in de vorm van staafdiagrammen. Daarnaast bevat een verbeterrapportage een prioriteitenlijst, die wordt gecreëerd door het belang dat patiënten hechten aan de verschillende kwaliteitsaspecten af te zetten tegen de ervaringen van patiënten met deze aspecten. Aspecten die patiënten/cliënten zeer belangrijk vinden, maar waarop de ervaring relatief negatief is, zouden de hoogste prioriteit moeten hebben voor verbetering. Vanuit patiëntenperspectief valt op deze onderwerpen namelijk een maximale kwaliteitswinst te behalen. Op basis van de rapportage kunnen zorgaanbieders dus prioriteiten stellen voor verbeterpunten en concrete verbeteracties formuleren.

\section{DE ROL VAN HET CENTRUM KLANTERVARING ZORG}

Om te zorgen voor de ontwikkeling, wetenschappelijke waarborging, implementatie en bewaking van de CQ-index is op 6 december 2006 het Centrum Klantervaring Zorg (CKZ) opgericht (voor meer informatie zie www.centrumklantervaringzorg.nl). Het CKZ is een onafhankelijke stichting, die gesubsidieerd wordt door het Fonds PGO. Het CKZ heeft een tripartiet bestuur met leden uit de kring van zorgverzekeraars, zorgaanbieders en patiënten/consumentenorganisaties.

Het CKZ heeft tot doel het systematisch, gestandaardiseerd (dat wil zeggen: volgens vaste procedures voor steekproeftrekking, dataverzameling en analyse) en vergelijkbaar (doen) meten van klantervaringen in de zorg en het openbaar publiceren van de resultaten van die metingen. Dat alles om de werking van de verzekeringsmarkt, de inkoopmarkt en de zorgmarkt te bevorderen.

Het CKZ ontwikkelt zelf geen meetinstrumenten. Het CKZ coördineert het ontwikkel- en meetprogramma rond CQI meetinstrumenten en zorgt daarnaast voor het beheer van de meetinstrumenten. De feitelijke ontwikkeling van een CQ-index vindt plaats bij diverse onderzoeksinstituten volgens de richtlijnen die in het Handboek CQI Ontwikkeling zijn 
beschreven (3). Deze richtlijnen worden opgesteld en beheerd door het CKZ. Na het doorlopen van de ontwikkelingsfase wordt een CQI meetinstrument op de website van het CKZ geplaatst, compleet met de protocollen en werkinstructies die horen bij de betreffende vragenlijst.

Het CKZ verricht zelf geen metingen. Het CKZ accrediteert zogeheten meetorganisaties en houdt toezicht op de metingen die zij uitvoeren, zodat de meetresultaten vergelijkbaar zijn. Resultaten van metingen die door een geaccrediteerde meetorganisatie zijn uitgevoerd met een meetinstrument uit de CQ-index en volgens de richtlijnen beschreven in het Handboek CQI Metingen, 3 komen in aanmerking voor het CQI-keurmerk. Openbare publicatie van de resultaten is een voorwaarde voor het verkrijgen van het keurmerk. Het CQI-keurmerk geeft aan dat de gepresenteerde klantervaringen betrouwbaar, valide, relevant en vergelijkbaar gemeten zijn.

\section{DE FINANCIERING VAN DE CQ-INDEX}

De ontwikkeling van een CQI meetinstrument wordt gefinancierd uit een combinatie van publieke en private middelen. De dataverzameling die noodzakelijk is voor het testen van een meetinstrument in ontwikkeling, wordt in het algemeen gefinancierd door private partijen: zorgaanbieders of zorgverzekeraars. Een belangrijke actor in de ontwikkeling van veel CQI meetinstrumenten is de Stichting Miletus, een samenwerkingsverband van vrijwel alle zorgverzekeraars. Deze Stichting Miletus coördineert en financiert de dataverzameling in het merendeel van de CQI ontwikkeltrajecten.

Een andere belangrijke actor is ZonMw. ZonMw financiert voor een groot deel van de CQI meetinstrumenten het onderzoek dat nodig is om tot een betrouwbare en valide vragenlijst te komen en financiert wetenschappelijk onderzoek naar klantervaringen in de zorg. Zie www.zonmw.nl bij programma 'Meten patiëntenervaringen'.

\section{BESCHOUWING}

Nederland behoort met Engeland en de Verenigde Staten tot één van de weinige landen waar klantervaringen met de zorg systematisch en gestandaardiseerd in beeld worden gebracht. Dit maakt het mogelijk om prestaties van zorgaanbieders onderling en in de tijd te vergelijken. Het belang daarvan voor de werking van het zorgstelsel en voor publieke verantwoording van collectieve middelen is groot. Maar we zijn er nog niet. Rond het meten van klantervaringen in de zorg zijn een aantal belangrijke wetenschappelijke vraagstukken tot nu toe onderbelicht gebleven. Daarbij gaat het bijvoorbeeld om de externe validiteit van vragenlijsten, de methode die gebruikt wordt om te corrigeren voor systematische verschillen in scoringsgedrag van respondenten en de presentatiewijze van keuze-informatie. Het is belangrijk dat de CQ-index aansluit bij de huidige kennis op het gebied van het meten van patiëntervaringen. Daarvoor is wetenschappelijke inbedding en vragenlijstoverstijgend, innovatief onderzoek noodzakelijk.

Tot op heden is vooral geïnvesteerd in het ontwikkelprogramma voor de CQ-index. Zeven CQI meetinstrumenten hebben de ontwikkelingsfase met succes doorlopen en ongeveer twintig CQI meetinstrumenten zijn in ontwikkeling. De onderwerpen van deze CQI meetinstrumenten variëren sterk. De keuze welke CQI meetinstrumenten ontwikkeld worden is op dit moment geen centraal geleid proces en is mede afhankelijk van de prioriteiten in het zorginkoopbeleid van de bij Stichting Miletus aangesloten verzekeraars, de prioriteiten bij actieve patiëntenorganisaties en de wervingskracht van onderzoeksgroepen die bepaalde ideeën willen uitwerken. De taak van het CKZ is om de meetinstrumentenontwikkeling te coördineren en af te stemmen over de verschillende sectoren heen. Daarnaast draagt het CKZ criteria aan op grond waarvan sectoroverstijgende prioriteiten zouden kunnen worden gesteld in de meetinstrumentontwikkeling. Zo heeft het CKZ zichzelf de vraag gesteld welke CQI meetinstrumenten er vanuit het maatschappelijk belang ontwikkeld moeten worden. Daarbij is geconstateerd dat voor een aantal belangrijke aandoeningen met een hoge ziektelast en die 
behoren tot de belangrijkste doodsoorzaken CQI meetinstrumenten nog ontbreken. Daarbij gaat het bijvoorbeeld om hartaandoeningen en kanker. Het is belangrijk om ook in de toekomst de ontwikkeling van de CQ-index te blijven spiegelen aan informatie over de kosten van een ziekte en over de ziektelast (zoals die verzameld wordt door het RIVM in onder andere de Volksgezondheids Toekomst Verkenning en in de Zorgbalans).

De CQ-index moet voorzien in de informatiebehoeften van veel verschillende eindgebruikers. Daarom zijn veel partijen betrokken bij de ontwikkeling van een CQI meetinstrument. De werkgroepen of begeleidingscommissies die onderzoekers adviseren gedurende het ontwikkelingstraject bestaan minimaal uit vertegenwoordigers van patiënten/cliënten, zorgverzekeraars en zorgaanbieders. De informatiebehoeften van deze partijen komen vaak wonderwel overeen, maar toch is er sprake van accentverschillen, vooral tussen aanbieders en verzekeraars. Zorgaanbieders hebben meer behoefte aan gedetailleerde informatie die vooral betrekking heeft op de eigen instelling of praktijk. Zorgverzekeraars zullen eerder vragen om vragenlijsten op een hoger abstractieniveau, die een hele zorgketen rond een bepaalde diagnosegroep betreffen. Deze accentverschillen kunnen leiden tot uitvoerige discussies binnen de begeleidende werkgroepen, die de voortgang van een ontwikkelproject niet altijd ten goede komen. Daarnaast kan de inbreng van meerdere partijen resulteren in lange vragenlijsten om zo te voldoen aan de verschillende informatiebehoeften. Maar het is noodzakelijk om alle partijen bij het ontwikkeltraject te betrekken. Uit internationaal vergelijkend onderzoek is namelijk gebleken dat samenwerking tussen publieke en private partijen en tussen zorgaanbieders en zorginkopers een belangrijke succesfactor is voor het ontwikkelen van prestatie-indicatoren. De samenwerking is niet alleen nodig voor het verzamelen van data maar ook voor het creëren van een omgeving waarin de prestatie-informatie door alle partijen als betrouwbaar wordt gezien. ${ }^{13}$

De doelstelling van de CQ-index is het bevorderen van de werking van de verzekeringsmarkt, de inkoopmarkt en de zorgmarkt. Voor het bestaansrecht van de CQindex is het dan ook van belang dat aangetoond kan worden dat de veronderstelde effecten inderdaad optreden. Als consumenten niet meer marktmacht vergaren doordat prestaties van aanbieders en verzekeraars transparant worden gemaakt, als de publicatie van prestaties niet leidt tot andere keuzen van consumenten en zorginkopers, als het openbaar maken van de prestaties van aanbieders niet uiteindelijk resulteert in een betere klantgerichtheid, dan heeft de CQ-index niet de beoogde uitwerking en verliest de meetstandaard zijn legitimiteit. Tot op heden is er weinig bekend over hoe patiënten/consumenten hun keuzen in de zorg maken en of ze hierbij de CQI informatie over de ervaringen van andere mensen (willen) gebruiken. Ook weten we nog onvoldoende of CQI informatie nuttige informatie oplevert voor zorgverzekeraars en zorgaanbieders voor respectievelijk het maken van zorginkoopafspraken en het opzetten van verbetertrajecten. In de komende jaren moet dan ook onderzocht worden of CQI informatie gebruikt wordt of kan worden door patiënten/cliënten, zorgverzekeraars en zorgaanbieders. Uiteindelijk moet uit onderzoek blijken of dat gebruik bijdraagt aan versterking van de positie van de cliënt en de werking van de zorg- en verzekeringsmarkt.

Daarnaast willen we benadrukken dat de CQ-index geen volledig beeld geeft van de kwaliteit van zorg in Nederland. De CQ-index laat enkel en alleen zien hoe de kwaliteit van zorg ervaren wordt door patiënten/cliënten en hierbij gaat het vooral om aspecten van klantgerichtheid (bijvoorbeeld bejegening, communicatie en toegankelijkheid). Aandoeningspecifieke CQI meetinstrumenten vragen daarnaast ook naar de 'ervaren effectiviteit' van zorg vanuit het perspectief van de klant. Zo wordt in de CQI Staaroperatie bijvoorbeeld gevraagd of respondenten nu beter of slechter dichtbij kunnen zien dan voor de operatie. Maar op dit moment is onvoldoende uitgekristalliseerd in hoeverre deze door de patiënt geleverde informatie samenhangt met de kwaliteit van de zorg en dus bruikbaar is bij het vergelijken van prestaties van aanbieders. Om een eerlijke vergelijking te kunnen maken is het daarnaast nodig om te corrigeren voor verschillen tussen respondenten in de ernst van de aandoening en eventuele comorbiditeit (zogenaamde case-mix adjustment). Deze informatie kan in het algemeen niet uit de CQ-index worden gehaald. De resultaten uit de 
CQ-index kunnen daarom niet los gezien worden van informatie uit andere bronnen met betrekking tot de effectiviteit en veiligheid van de zorg. Binnen verschillende zorgsectoren worden zogenaamde prestatie-indicatoren ontwikkeld. Hierbij wordt een onderscheid gemaakt tussen zorginhoudelijke indicatoren en klantervaringen. De zorginhoudelijke indicatoren geven inzicht in de effectiviteit en veiligheid van de zorg en zijn vooral gebaseerd op registraties van de instellingen zelf. Klantervaringen kunnen gemeten worden met de CQ-index.

\section{THE CQ-INDEX: MEASURING CLIENT EXPERIENCES WITH HEALTH CARE}

In this article, we describe the Consumer Quality Index (CQ-index or CQI). The CQ-index is a standardized method for measuring experiences of patients/clients with health care. An important feature is that patients/clients, health care providers and health insurers are all involved in the development of CQI questionnaires. At the moment, seven CQI questionnaires are available and about twenty CQI questionnaires are being developed. The objective of the CQindex is to advance transparency on the performances of health care providers and health insurers concerning responsiveness. The information is meant for consumers when choosing their health care provider and for health insurers when contracting health care selectively. Health care providers should be able to use the information for implementing quality improvement activities. The Centre for Consumer Experiences in Healthcare is responsible for the development, scientific value, implementation and marking of the CQ-index. The development of CQI questionnaires and scientific research on the CQ-index is financed by both public en private resources. Upcoming years, we have to make sure that CQI questionnaires are developed for the most important health care sectors and it should be determined whether the intended effects on managed competition in health care indeed occur.

\section{LITERATUUR}

1. Ministerie van VWS. Vraag aan bod. Den Haag: VWS, 2000.

2. Cleary $P$, Edgman-Levitan $S$. Health care quality. Incorporating consumer perspectives. JAMA 1997;19:1608-12.

Sixma H, Delnoij D. Handboek CQI meetinstrumenten: Een handleiding voor de

3. ontwikkeling en het gebruik van Consumer Quality Index (CQI) vragenlijsten. Utrecht: NIVEL, 2007.

Delnoij D, Ten Asbroek G, Arah O et al. Made in the USA: The import of American

4. Consumer Assessment of Health Plan Surveys (CAHPS) into the Dutch social insurance system. Eur J Public Health 2004;14:supplement:43.

Hargraves J, Hays R, Cleary P. Psychometric properties of the Consumer Assessment of

5. Health Plans Study (CAHPS(R)) 2.0 Adult Core Survey. Health Services Res 2003;38:1509-27.

Hays R, Shaul J, Williams V et al. Psychometric properties of the CAHPS 1.0 survey

6. measures. Consumer Assessment of Health Plans Study. Medical Care 1999;37:MS22-31.

Delnoij DMJ, Ten Asbroek G, Onyebuchi AA et al. Made in the USA: The import of

7. American Consumer Assessment of Health Plan Surveys (CAHPS(R)) into the Dutch social insurance system. Eur J Public Health 2006;16:652-659.

8. Arah OA, Ten Asbroek AHA, Delnoij DM et al. The psychometric properties of the Dutch 
version of the Hospital-level Consumer Assessment of Health Plans Survey instrument. Health Services Res 2006;41:284-301.

Nijkamp MD, Sixma H, Afman H, Hiddema F, Koopmans SA. Quality of care from the

9. perspective of the cataract patient. QUOTE cataract questionnaire. J Cataract Refractive Surgery 2002;28:1924-31.

Sixma H, Kerssens J, Van Campen C, Peters L. Quality of care from the patients'

10. perspective: From theoretical concept to a new measuring instrument. Health Expectations 1998;1:82-95.

Sixma H, Campen C van, Kerssens J, Peters L. Onderzoekprogramma Kwaliteit van

11. Zorg. De QUOTE-vragenlijsten. Kwaliteit van zorg vanuit patiëntenperspectief; vier nieuwe meetinstrumenten. Utrecht: NIVEL, 1998.

12. Westert GP, Berg MJ van den, Koolman X, Verkleij H (red). Zorgbalans 2008. De prestaties van de Nederlandse gezondheidszorg. Bilthoven: RIVM, 2008.

13. Lugtenberg M, Westert GP. Kwaliteit van de gezondheidszorg en keuze-informatie voor burgers. Een internationale verkenning van initiatieven. Tilburg: TRANZO, 2007.

\section{BOX EN TABELEN}

Box 1. Gebruikers van de CQ-index en hun informatiebehoefte

Consumenten

Patiënten- en cliëntenorganisaties

Zorgverzekeraars

Overheid

Inspectie voor de Gezondheidszorg

Managers en professionals

Onderzoekers $\rightarrow$ Keuze-informatie

$\rightarrow$ Belangenbehartigingsinformatie

$\rightarrow$ Zorginkoopinformatie

$\rightarrow$ Monitorinformatie

$\rightarrow$ Toezichtinformatie

$\rightarrow$ Verbeterinformatie

$\rightarrow$ Informatie voor beantwoorden

wetenschappelijke vragen

\section{Box 2.. CQI meetinstrumenten die in ontwikkeling zijn}

CQI Ambulante GGZ

CQI Astma

CQI Coloncarcinoom

CQI COPD ketenzorg

CQI Eerstelijnszorg

CQI Farmaceutische zorg

CQI Fertiliteitszorg

CQI Fysiotherapie

CQI Geboortezorg

CQI Huisartsenposten

CQI Huishoudelijke verzorging

CQI Hulpmiddelen CQI Jeugdgezondheidszorg

CQI Langdurige en klinische GGZ

CQI Maatschappelijke opvang

CQI Mammacare

CQI Nierdialyse

CQI Palliatieve zorg

CQI Reumatoïde Artritis ketenzorg

CQI Revalidatiezorg

CQI Rughernia

CQI Spataderzorg

CQI Ziekenhuiszorg 